\title{
The efficacy of talent selection criteria in the Australian Football League
}

\section{Courtney Sullivan, Thomas Kempton, Patrick Ward \& Aaron J. Coutts}

To cite this article: Courtney Sullivan, Thomas Kempton, Patrick Ward \& Aaron J. Coutts (2020): The efficacy of talent selection criteria in the Australian Football League, Journal of Sports Sciences, DOI: 10.1080/02640414.2020.1734309

To link to this article: https://doi.org/10.1080/02640414.2020.1734309

\section{Published online: 25 Feb 2020.}

Submit your article to this journal ๔

Q View related articles $₫$

View Crossmark data $\nearrow$ 


\title{
The efficacy of talent selection criteria in the Australian Football League
}

\author{
Courtney Sullivan ${ }^{\mathrm{a}, \mathrm{b}}$, Thomas Kempton ${ }^{\mathrm{a}, \mathrm{b}}$, Patrick Ward ${ }^{\mathrm{a}, \mathrm{c}}$ and Aaron J. Coutts $\mathbb{( D}^{\mathrm{a}}$ \\ aSport and Exercise Discipline Group, Faculty of Health, University of Technology Sydney (UTS), Australia; bSports Science Department, Carlton \\ Football Club, Carlton, Australia; 'Seattle Seahawks, Seattle, USA
}

\section{ABSTRACT}

This study investigated the association between talent selection criteria, draft order and match performance in professional Australian Football players. Physical performance results from the Australian Football League (AFL) National Draft combine and non-performance based talent selection criteria were collated for all players drafted in the National Draft with selections 1-80 between 2003 and 2008 $(n=318)$. Match performance was assessed via the AFL Player Ranking metric that was provided by a commercial statistical provider (Champion Data Pty Ltd). A combination of stepwise multiple regression and linear mixed model analyses examined the influence of National Draft combine physical performance assessments and non-performance based talent selection criteria on draft order and future match performance. Earlier draft selection was associated with Under-18 all Australian team selection, height, Under-18 National Championship participation and indigenous status. The $20 \mathrm{~m}$ sprint and state of origin were associated with later draft selection. Under-18 all Australian team selection increased both Player Ranking/game and total Player Ranking. Under-18 all Australian team selection displays efficacy for selecting players with the potential for success.
ARTICLE HISTORY

Accepted 4 November 2019

\section{KEYWORDS}

Talent selection; linear mixed modelling; match performance; recruiting

\section{Introduction}

Talent selection is a crucial element in the pursuit of success for professional Australian Football clubs. The process of talent selection in the Australian Football League (AFL) occurs via the AFL National Draft which provides AFL teams with the opportunity to select players whom they believe will advantageously contribute to team performance. The AFL draft can also act as an equalisation strategy for the league with selections allocated to teams in a reverse order based on final ladder position from the preceding season. Specifically, poorer performing AFL teams (ranked lower on the ladder after the previous season) are allocated draft selections further up the selection sequence in contrast to teams who finish higher on the end of season ladder who are allocated draft selections later in the sequence.

To facilitate the talent selection process, the AFL host an annual National Draft Combine event whereby talent identified junior players undergo a selection of physiological, technical skill and anthropometrical assessments under the observation of talent scouts. The AFL also host the Under-18 National Championship competition consisting of talent identified junior players representing their state in a 4-6 week tournament. During the tournament, the physical activity and technical profiles of players are recorded via global positioning system micro technology and the commercial statistics provider for the AFL, Champion Data Pty Ltd. From the Under-18 National Championship tournament, the Under-18 All Australian team is selected by an expert panel with selection representing the highest level of acclaim for a junior Australian Football player. In addition to the objective performance data accessible from the National Draft combine and Under-18 National Championship tournament, both events allow AFL recruiters the opportunity to subjectively evaluate the best, talent identified junior players with the view to identify suitable prospective draftees.

Previous research has examined the relationship between physical and technical match activity profiles from the Under18 National Championship tournament and draft order in the AFL reporting that players demonstrating superior contested skills were prioritized within a draft round (Woods, Veale, Collier, \& Robertson, 2016). Beyond draft order, several studies have investigated draft outcome finding that drafted players accumulated more contested possessions and inside 50's during the Under-18 National Championship tournament (Woods, Joyce, \& Robertson, 2015) and were taller, faster over $20 \mathrm{~m}$ and had a greater aerobic capacity (multi-stage fitness test) (Robertson, Woods, \& Gastin, 2014) than non-drafted players. Despite these National Draft combine performance assessments differentiating between drafted and non-drafted players, relationships between National Draft combine performance assessments and draft order are yet to be examined.

Given one of the aims of selecting players in the AFL draft is to select players with the potential to contribute to team performance, it is imperative that the talent selection criteria on which draft selection decisions are based displays efficacy (Abbott \& Collins, 2002; Vaeyens, Lenoir, Williams, \& Philippaerts, 2008). This requires a measure of individual match performance however, this is a difficult task within a team sport environment where performance is measured in the context of the team (i.e. match outcome). Accordingly, surrogate measures have been proposed within the AFL 
including the number of career matches played (Burgess, Naughton, \& Hopkins, 2012; Pyne, Gardner, Sheehan, \& Hopkins, 2005) and subjective evaluations of player potential and value (Pyne et al., 2005). An alternative was adopted in earlier research that applied regression analysis to determine the technical match statistics most associated with a winning score margin in Australian Football (Stewart, Mitchell, \& Stavros, 2007). Using these statistics, the authors developed an 11variable player ranking model to assess and compare players in the AFL (Stewart et al., 2007). Using a similar approach to Stewart et al., Champion Data Pty Ltd have developed a metric termed the "AFL Player Rankings". These ranking measures are an aggregate measure of player match performance that is based upon a player's involvement in selected match activities. The match activities are allocated a pre-determined positive or negative numerical value with the summative score indicative of an individual's influence on a match. Although no external validation of AFL Player Rankings has been performed, previous research has found that earlier draft round selections acquired a greater AFL Player Ranking than those selected further down the draft order (Mitchell, Stavros, \& Stewart, 2011) and that AFL Player Ranking (aggregate score for the team) was higher in quarters won when compared to quarters lost (Sullivan et al., 2013b). Accordingly, AFL Player Rankings remain widely used as a measure of individual match performance within AFL scientific research (Hiscock, Dawson, Heasman, \& Peeling, 2012; Mooney et al., 2011; Stewart, Stavros, Phillips, Mitchell, \& Barake, 2016).

Previous research examining the relationship between talent selection criteria and individual match performance has been performed in the National Football League (NFL) (Berri \& Simmons, 2011; Kuzmits \& Adams, 2008; Mulholland \& Jensen, 2014; Teramoto, Cross, \& Willick, 2016) and the National Basketball Association (NBA) (Berri, Brook, \& Fenn, 2011; Teramoto, Cross, Rieger, Maak, \& Willick, 2017). These studies have presented conflicting findings with some confirming the efficacy of select talent selection criteria (Kuzmits \& Adams, 2008; Mulholland \& Jensen, 2014; Teramoto et al., 2017, 2016) while others have reported a lack of agreement between the characteristics valued by recruitment staff and those that are associated with future performance in team sport athletes (Berri et al., 2011; Berri \& Simmons, 2011). These differences may be attributed to variation in match performance measures, time spans, sample sizes and statistical analysis techniques between studies. Furthermore, the variables associated with both draft order and future match performance in team sport athletes appear to be specific to playing position (Kuzmits \& Adams, 2008). For example, a different combination of NFL Draft Combine physical activity measures were shown to be associated with future match performance for the running back playing position (10 yard sprint) compared to the wide receiver playing position (height, weight and vertical jump) in the NFL (Teramoto et al., 2016). Given recent research has identified differences in objective match performance data between player roles in the AFL (McIntosh, Kovalchik, \& Robertson, 2018a), future research examining match performance in professional Australian Football should account for playing position.

In addition to Draft Combine physical performance assessments, a number of studies have reported an association between non-performance based talent selection criteria and future match performance in the NBA and the NFL including age (Berri et al., 2011), games played in National Championship tournaments (Berri et al., 2011) and the quality of the team and the competition played in as a junior athlete (Berri et al., 2011; Mulholland \& Jensen, 2014). Of relevance to the AFL, is the relative age effect (RAE) which is a phenomenon that relates to selection bias towards individual athletes born earlier in the year (Cobley, Baker, Wattie, \& McKenna, 2009). The RAE has been demonstrated in a number of team sports (Cobley et al., 2009) including Australian Football (Coutts, Kempton, \& Vaeyens, 2014; Tribolet, Watsford, Coutts, Smith, \& Fransen, 2019) with recent research indicating that the RAE is prevalent throughout the AFL talent pathway (Tribolet et al., 2019).

Despite previous research examining the efficacy of talent selection criteria being performed in other professional team sport leagues, we are yet to see a similar investigation in the AFL. This warrants further research, as identifying the talent selection criteria that is associated with both draft order and future match performance could hold important implications in the talent selection strategies employed by AFL recruiters. Therefore, the aim of this investigation was to examine the talent selection criteria associated with draft order and future match performance in professional Australian Football. We hypothesise based on previous research in the AFL (Robertson et al., 2014) that superior Draft Combine physical performance and some non-performance based criteria will be meaningfully associated with draft order and future match performance in the AFL.

\section{Methods}

A retrospective, longitudinal research design examined the relationship between select National Draft combine physical performance assessments and non-performance based talent selection criteria on draft order and match performance in the AFL. Permission to the AFL National Draft, Under-18 National Championship tournament and Draft Combine data was granted by the AFL. Under-18 All Australian team details were retrieved from the relevant AFL Record Season Guide released annually by the AFL. The independent variables selected for analysis were chosen using both a domain expertise (Berri et al., 2011; Burgess et al., 2012; Mulholland \& Jensen, 2014; Robertson et al., 2014) and an exploratory approach. Although previous research in the AFL has demonstrated that specific Draft Combine physical performance variables are related to draft outcome (Robertson et al., 2014), the ability of these same variables to predict draft order and future match performance was unknown given the homogeneity of drafted players. Accordingly, all Draft Combine physical performance variables where sufficient data was available were included in the present analysis. Details of the independent variables used in the current study are presented in Table 1.

Once retrieved, draft data was delimited to include selections 1-80 drafted for the first time to a professional Australian Football club in the AFL National Draft between 2003 and 2008 (retained $n=428$, excluded $n=98$ ). Furthermore, to investigate match performance only those who had remained on an AFL playing roster for five seasons following being drafted were 
Table 1. Descriptive statistics for the covariates included in the multiple regression and mixed model specification.

\begin{tabular}{|c|c|c|c|c|}
\hline Covariate & $n$ & Type & Units/classification & $\begin{array}{c}\text { Mean } \pm \text { SD/ } \\
\text { Proportion (\%) }\end{array}$ \\
\hline \multicolumn{5}{|l|}{ National Draft Combine } \\
\hline Height & 232 & Continuous & $\mathrm{cm}$ & $188.0 \pm 6.9$ \\
\hline National Draft Combine sum of 7 skinfolds & 205 & Continuous & $\mathrm{mm}$ & $53.1 \pm 10.8$ \\
\hline National Draft Combine $20 \mathrm{~m}$ sprint & 173 & Continuous & seconds & $3.03 \pm 0.08$ \\
\hline National Draft Combine agility & 168 & Continuous & seconds & $8.54 \pm 0.29$ \\
\hline National Draft Combine multi-stage fitness test & 157 & Continuous & metres & $2486 \pm 220$ \\
\hline \multicolumn{5}{|l|}{ Non-performance based } \\
\hline Indigenous status & 317 & Dichotomous & $0=$ No, $1=$ Yes & $91.5 / 8.5$ \\
\hline Birth month & 317 & Dichotomous & $0=$ Jan-Jun, $1=$ Jul-Dec & $36.9 / 63.1$ \\
\hline State of origin at draft & 317 & Dichotomous & $0=\mathrm{VIC}, 1=$ other & $49.2 / 50.5$ \\
\hline \multicolumn{5}{|l|}{ Performance based } \\
\hline U18 All Australian selection & 317 & Dichotomous & $0=$ No, $1=$ Yes & $73.5 / 26.2$ \\
\hline U18 National Championship tournament participation & 317 & Dichotomous & $0=$ No, $1=$ Yes & $62.5 / 37.2$ \\
\hline U18 National Championship tournament GF outcome & 317 & Dichotomous & $0=$ Lose, $1=$ Win & $87.7 / 12.0$ \\
\hline
\end{tabular}

U18: Under 18, GF: grand final, Jan: January, Jun: June, Jul: July, Dec: December.

included in the analysis therefore a further 111 samples were excluded resulting in a total of 317 samples that were retained for analysis. Season 2008 was the final year used in the analysis to avoid the disadvantage to players yet to complete their careers. In addition to the AFL National Draft, players may also be selected via the rookie or pre-season Draft which takes place annually after the AFL National draft. Despite this, our data was delimited to include National Draft selections only as the talent selection criteria that is used to select these players is likely different given these players have been overlooked in the National Draft. For the purposes of our analysis, drafted players were assigned the number representing the order in which they were drafted.

Match performance was assessed by the AFL Player Ranking metric (Champion Data Pty Ltd). Champion Data conducts notational analyses on the technical skill involvements of individual players and teams during professional Australian Football match-play. The AFL Player Ranking metric is an aggregate performance score geared towards winning factors. A positive rating is allocated to each effective skill execution and a negative rating is allocated to an ineffective skill execution with the summative score representing the impact that an individual has on a match. The total AFL Player Ranking points (total Player Ranking) and the average AFL Player Ranking points per game (Player Ranking/game) achieved within the first five seasons of playing careers (seasons 2004-2013 depending on draft year) were retrieved and aligned with National Draft order data in a custom Microsoft Excel spreadsheet (Microsoft ${ }^{\circledR}$, Redmond, WA, USA). Player Ranking/game was included to provide a measure that was independent of career games played (Teramoto et al., 2016). Ethics approval for secondary analyses was granted by the University of Technology Sydney (UTS) Human Research Ethics Committee prior to the commencement of the study (HREC2014000232).

We first modelled the relationship between talent selection criteria and draft order. To do this, we built a linear mixed model with a random effect for playing position (forward, midfielder, defender, ruckman) using the Ime4 package in R Studio statistical software (Version 0.99.489, R Foundation for Statistical Computing). Players were assigned to the playing position according to Champion Data and where they played the majority of their career. Prior to analysis, residual plots were observed to ensure that the assumption of normality was not violated. Additionally, collinearity tolerance statistics were calculated to determine the correlation between the predictor variables, and any variable that had a tolerance level of less than.10 was not included in the model. The necessity of the random effect was assessed by a likelihood ratio test statistic representing the difference in the -2 log-likelihood values of a model with the random effect included and a model without (West, Welch, \& Galecki, 2014). Initial test diagnostics indicated that a mixed model approach was not required $\left(x^{2}(3)=0.67\right.$, $\mathrm{p}=0.88, \mathrm{AIC}=2810.70)$. Accordingly, a stepwise multiple regression was employed to determine the individual player characteristics associated with draft order in the AFL. Given stepwise regression has been shown to have a number of limitations including biased parameter estimates and the reliance on selecting a single best model to describe the data generating processes (Whittingham, Stephans, Bradbury, \& Freckleton, 2006), we have chosen to report the top 5 models identified by stepwise regression. Akaike information criterion was used to compare the explanatory ability of the top 5 models due to the monotonic increase in $R^{2}$ values when increasing model parameters. Ten-fold cross-validation was performed on the model with the lowest AIC to determine the prediction error with regression model performance assessed using the mean absolute error (MAE) and the root mean squared error (RMSE).

We also modelled the relationship between talent selection criteria and AFL match performance by building two separate models using total Player Ranking and Player Ranking/game as dependent variables. Linear mixed modelling was used for this part of the analysis with both models including a random effect for playing position (forward, midfielder, defender, ruckman). These models were fitted to the match performance data using the R Studio statistical software. A forward selection construction strategy was employed, beginning with a reference model containing only a fixed intercept and level 2 random factor (playing position) (West et al., 2014). The model was then developed by adding each single level 1 fixed effect (performance assessment) with the fixed effect retained if it improved the model information criteria compared to the previous model as determined by a likelihood ratio test (Cnaan, Laird, \& Slasor, 
1997). Level 1 fixed effects were also tested for random coefficient effects by comparing a model containing the random effect to that containing the fixed effect for each covariate. The intra-class correlation coefficient (ICC) was used to determine the similarity of observed responses within the positional cluster.

\section{Results}

The descriptive statistics for each covariate used in the multiple regression and mixed model specifications are displayed in Table 1. The variables contained in each of the top five models following the stepwise regression according to AIC are displayed in Figure 1. The stepwise multiple regression analysis revealed that $29 \%$ of the adjusted variance in draft order could be explained by the following individual player characteristics; Under-18 all Australian team selection, height, state of origin, $20 \mathrm{~m}$ sprint, indigenous status and participation in the Under18 National championship tournament $(Y=68.78-14.48$ Under18 All Australian team selection -0.82 height +8.38 state of origin + $37.9220 \mathrm{~m}$ sprint -8.52 indigenous status - 5.82 Under-18 National championship tournament participation) [Adjusted $\mathrm{R}^{2}=0.288 ; F_{6,151}=11.62 ;$ AIC 849.01]. Estimates, standard errors and $95 \%$ confidence intervals are shown in Table 2.

Results for the linear mixed model analysis have been reported in Table 3. For both linear mixed models investigating match performance, the construction process was optimised by including the random intercept effect for playing position demonstrating that there was statistically significant variance by position in both Player Ranking/game and total Player Ranking. The level one covariate Under-18 All Australian team selection increased both Player Ranking/game and total Player
Ranking. There were no random coefficient effects for any level one covariate in either model, indicating that these effects were consistent across positional groups. The ICC for individual players within each position cluster was 0.07 and 0.04 for average and total AFL Player Ranking, respectively.

\section{Discussion}

This study examined the influence of various individual player characteristics on draft order and subsequent match performance (AFL Player Rankings) in professional Australian Football. We found that draft order could be explained by a combination of talent selection criteria including the Draft Combine variables of height and $20 \mathrm{~m}$ sprint, Under-18 All Australian team selection and National Championship tournament participation, state of origin and indigenous status. Of those variables, only Under-18 All Australian team selection was also associated with future match performance. These findings have important implications for the talent selection process in professional Australian Football.

Australian Football League Draft Combine variables including height and $20 \mathrm{~m}$ sprint were associated with AFL Draft order. Specifically, taller athletes were selected with earlier round draft selections while those who were slower over $20 \mathrm{~m}$, selected later in the draft. The present results are supported by previous research highlighting the importance of height and speed over $20 \mathrm{~m}$, as assessed at the AFL National Draft combine, in attaining higher selection (Pyne et al., 2005; Robertson et al., 2014). Similar findings were also reported in the NBA with a 1 inch increase in height improving draft order by 1 position (Berri et al., 2011). When taken together, it appears that height influences both draft outcome and draft order with taller athletes prioritized by AFL recruiters in the National Draft.

\begin{tabular}{|c|c|c|c|c|c|}
\hline Covariate & Model 1 & Model 2 & Model 3 & Model 4 & Model 5 \\
\hline Height & -0.78 & -0.78 & -0.84 & -0.82 & -0.82 \\
\hline $\begin{array}{l}\text { National Draft Combine sum of } 7 \\
\text { skinfolds }\end{array}$ & -0.11 & -0.12 & -0.12 & & \\
\hline $\begin{array}{l}\text { National Draft Combine } 20 \mathrm{~m} \\
\text { sprint }\end{array}$ & 43.20 & 43.27 & 39.24 & 37.26 & 37.92 \\
\hline National Draft Combine agility & -4.21 & -3.98 & & & \\
\hline $\begin{array}{l}\text { National Draft Combine multi- } \\
\text { stage fitness test }\end{array}$ & 0.00 & & & & \\
\hline Indigenous & -7.66 & -7.62 & -8.62 & -8.60 & -8.52 \\
\hline Birth month & 2.62 & 2.49 & 2.45 & 2.50 & \\
\hline State of origin at draft & 7.86 & 7.94 & 7.89 & 8.07 & 8.38 \\
\hline U18 All Australian selection & -14.46 & -14.47 & -14.33 & -14.65 & -14.48 \\
\hline $\begin{array}{l}\text { U18 National Championship } \\
\text { tournament participation }\end{array}$ & -5.57 & -5.62 & -5.98 & -5.75 & -5.82 \\
\hline \multicolumn{6}{|l|}{$\begin{array}{l}\text { U18 National Championship } \\
\text { tournament GF outcome }\end{array}$} \\
\hline AIC & 854.24 & 852.42 & 851.15 & 849.88 & 849.01 \\
\hline
\end{tabular}

Figure 1. Visualisation of the variables included in the top 5 models according to AIC. Shaded regions indicate the inclusion of that variable in the model and the corresponding beta coefficient estimate. 
Table 2. Stepwise multiple regression model results. Dependant variable is "AFL draft order".

\begin{tabular}{lcccc}
\hline Covariate & Estimate & $\mathrm{SE}$ & $\mathrm{LCl}$ & $\mathrm{UCl}$ \\
\hline Intercept & 68.78 & 47.01 & -24.11 & 161.67 \\
20 m sprint & 37.92 & 15.33 & 7.63 & 68.20 \\
U18 All Australian selection & -14.48 & 2.43 & -19.27 & -9.68 \\
Indigenous & -8.52 & 3.86 & -16.15 & -0.89 \\
State of origin & 8.38 & 2.39 & 3.65 & 13.11 \\
U18 NC participation & -5.82 & 2.35 & -10.46 & -1.17 \\
Height & -0.82 & 0.19 & -1.20 & -0.43 \\
AIC & 849.01 & & & \\
Adjusted R & 0.29 & & & \\
RMSE & 14.95 & & & \\
MAE & 12.63 & & & \\
\hline
\end{tabular}

Estimate: beta coefficient estimate; S.E.: standard error; LCl: lower $95 \%$ confidence interval; upper $95 \%$ confidence interval; RMSE: root mean squared error; MAE: mean absolute error; U18: Under 18, NC: National Championship tournament

This study was the first to examine the relationship between non-performance-based talent selection criteria and draft order in the AFL. The findings demonstrate that players originating from outside Victoria were taken in the AFL National Draft with later round draft selections in comparison to their Victorian counterparts. Additionally, players who identified as indigenous, those who participated in the Under-18 National Championship tournament and those who were selected in the Under-18 All Australian team were selected earlier in the AFL Draft. The findings regarding Under-18 National Championship tournament participation and Under-18 All Australian team selection indicate that recruitment staff in the AFL value players who progress throughout the AFL talent pathway and in turn, select them earlier in the National Draft. Although the influence of indigenous status on AFL Draft Order has not previously been investigated, early research has demonstrated that indigenous AFL players from season 2006 and 2007 achieved more AFL Player Ranking points per game than an equivalent non-indigenous player (Mitchell et al., 2011) providing a justification for prioritizing indigenous players in the AFL Draft. The demonstrated bias towards prospective Victorian based draftees was an unexpected finding but could have several explanations. There are two teams that represent Victoria in the Under-18 National Championship tournament one team from the Melbourne metropolitan area and one from the rural areas of Victoria - with the remaining teams representing other Australian states. Accordingly, there are twice as many Victorian players exposed to AFL talent scouts. In combination with the finding that Under-18 AFL National Championship participation positively influences draft order, it is possible that this increased exposure of Victorian-based prospective draftees in the Under-18 National Championship tournament results in them being selected further up the draft order when compared to their interstate counterparts. Alternatively, this finding could reflect the perception that the Under-18 Victorian league (NAB League, formally TAC Cup) is stronger than the other underage leagues. This is supported by previous research reporting that Under-18 National Championship and AFL drafted players from the TAC Cup competition were faster over $20 \mathrm{~m}$, had a higher vertical jump and greater aerobic fitness when compared to players from the Under-18 Western Australian and South Australian competitions (WAFL and SANFL) (Robertson et al., 2014).

Despite these findings regarding AFL Draft order, only Under-18 All Australian team selection demonstrated a relationship with both Draft order and future match performance (AFL Player Ranking/game and total Player Ranking). Specifically, selection in the Under-18 All Australian team resulted in a 15-position improvement in AFL Draft order. Furthermore, Under-18 All Australian players achieved an extra 9 Player Ranking points per game and 1490 points over the course of their first 5 seasons when compared to players who were not selected in the Under-18 All Australian team. This confirms the efficacy of talent selection at the junior, elite level of Australian Football and the subsequent effectiveness of recruitment staff in using the talent identification resources facilitated by the AFL to assist in their selection strategies on draft day. However, the lack of a relationship between height, state of origin, $20 \mathrm{~m}$ sprint, indigenous status, Under-18 National Championship participation and AFL Player Rankings indicates that these variables may be overvalued by recruitment staff in the AFL Draft. While previous research supports this finding regarding height and speed - where only trivial to small differences in the number of career games played by players one standard deviation above and below the mean for height $(1.86 \pm 0.07 \mathrm{~m})$ and speed over $20 \mathrm{~m}$ (3.04 \pm 0.10$)$ (Burgess et al., 2012) were found - this is the first investigation to examine non-performance based talent selection criteria in the AFL and the influence on draft order. It is important to acknowledge that although results from the present study may suggest that certain talent selection criteria are not prerequisite characteristics for obtaining AFL Player Ranking points, it is also possible that this is due to limitations with the AFL Player Ranking metric. For example, AFL Player Rankings may be geared towards technical match statistics that are frequently performed by shorter players. Indeed midfield players typically accumulate more disposals than key position players and are often the shortest players on the team (Gray \& Jenkins, 2010). Given the contribution of disposal count to the Player Ranking metric (Sullivan et al., 2013a), it is possible that taller players and the technical match statistics that key position players frequently perform are unrepresented by AFL Player Rankings providing a possible explanation as to why height was unrelated to the AFL Player Ranking metric. Likewise, it is possible that limitations with the AFL Player Ranking metric may be responsible for the lack of relationship identified between the other variables associated with draft order and AFL Player

Table 3. Effects of significant covariates on player ranking/game and total player ranking in professional Australian football.

\begin{tabular}{|c|c|c|c|c|c|c|c|c|}
\hline \multirow[b]{2}{*}{ Fixed Effects } & \multicolumn{4}{|c|}{ Player Ranking/game (Model 1) } & \multicolumn{4}{|c|}{ Total Player Ranking (Model 2) } \\
\hline & Estimate & $95 \% \mathrm{Cl}$ & $\mathrm{df}$ & t value & Estimate & $95 \% \mathrm{Cl}$ & $\mathrm{df}$ & t value \\
\hline Intercept (au) & 57.73 & $51.83,63.33$ & 3.15 & 21.86 & 2641.0 & $1957.41,3296.46$ & 3.6 & 8.50 \\
\hline U18 All Australian selection & 8.81 & $4.63,13.12$ & 313.28 & 4.08 & 1490.9 & $891.49,2111.68$ & 542.0 & 4.82 \\
\hline
\end{tabular}

Cl: confidence interval; df: degrees of freedom; U18: Under 18 
Rankings. Future research should investigate the talent selection criteria examined in the present study and other measures of match performance in the AFL such as the AFL Player Ratings - an objective player analysis system developed by Champion Data which has recently been externally validated (Mclntosh, Kovalchik, \& Robertson, 2018b).

We found no evidence of the influence of the RAE on draft order despite previous research demonstrating a clear selection bias in the birth distribution of adolescent draftees in the AFL towards those players born earlier in the year (Coutts et al., 2014). More recently, additional research has confirmed the presence of the RAE throughout the AFL talent pathway, from Under-12 Academy players through to Brownlow Vote recipients, reporting a clear bias towards those born in quartiles 1 and 2 of the selection year (Tribolet et al., 2019). Of note, the present study assessed half-year birth distributions only with previous research also investigating quartile birth distributions (Coutts et al., 2014; Tribolet et al., 2019). Additionally, previous research reporting the prevalence of the RAE in professional Australian Football compared cohorts to either the Australian national population (Coutts et al., 2014; Tribolet et al., 2019) or the sample where that cohort originated from (Tribolet et al., 2019). Future research should investigate the birth quartile distribution of players drafted to the AFL and examine if birth quartiles influence AFL Draft order.

A distinct advantage of the mixed model approach taken in the present study was the ability to account for position a common limitation of previous research investigating talent identification and selection in Australian Football (Burgess et al., 2012; Robertson et al., 2014). These previous investigations have reported that some physical performance tests performed at the National Draft combine are associated with various measures of success however, the relevance of the findings for all position groups are unclear. Indeed, the physical requirements of Australian Football match-play have been shown to vary by playing position (Coutts et al., 2014). However, our results suggest that drafted players who were selected in the Under-18 All Australian team - when accounting for playing position - achieve a greater total Player Ranking and Player Ranking/game score in the 5 years after being drafted than players who were drafted without the acclaim of Under-18 All Australian team selection.

The data presented here are the first to show the individual player characteristics that influence draft order and subsequent match performance in the AFL. There are however, a few limitations which should be acknowledged. First, the present results show that $71 \%$ of the variance in draft order could not be explained by the individual player characteristics included in the multiple regression component of this study. Of note, technical skill and decision-making assessments are now included in the AFL National Draft Combine testing schedule (kicking efficiency, 2009; handball, 2010; goal kicking, 2012), however it will be some time before an adequate sample size is available for analysis. Given the results of recent research, it is likely that match-based physical and technical performance measures from the Under-18 National Championship tournament (Woods et al., 2016) in addition to tactical abilities related to decision making (Woods, Raynor, Bruce, \& McDonald, 2016) may improve the current models.
Furthermore, it is likely that game sense and psychological attributes such as leadership and competitiveness contribute to the decisions made in the AFL National Draft ("Australian Football League. AFL Youth Coaching Manual," 2012). In regards to match performance, the importance of developmental biography cannot be discounted with recent research demonstrating that super elite athletes (Olympic and World Champion) could be differentiated from elite athletes (International) based on a combination of psychosocial aspects, coach and family relationships and practice (Güllich et al., 2019). While we were unable to determine the influence of these additional individual characteristics on draft order and match performance, they provide direction for future research in this area.

\section{Conclusion}

Results from this study demonstrate that recruitment staff use a variety of talent selection criteria when making decisions on selections in the AFL Draft however, the lack of a relationship between these variables and future match performance questions their use in current talent selection practices. Nonetheless, Under-18 All Australian team selection appears to be highly valued by recruitment staff and in turn is positively associated with individual player match performance. This finding confirms the efficacy of Under-18 All Australian team selection as criteria for selecting players with the potential for success in professional Australian Football.

\section{Disclosure Statement}

No potential conflict of interest was reported by the authors.

\section{ORCID}

Aaron J. Coutts (iD) http://orcid.org/0000-0002-1782-7691

\section{References}

Abbott, A., \& Collins, D. (2002). A theoretical and empirical analysis of a state of the art talent identification model. High Ability Studies, 13(2), 157-178.

Australian Football League. AFL youth coaching manual. (2012). Retrieved from http://www.aflcommunityclub.com.au/fileadmin/user_upload/ Coach_AFL/coaching_manual/2012_Youth_Coaching_Manual.pdf

Berri, D. J., Brook, S. L., \& Fenn, A. J. (2011). From college to the pros: Predicting the NBA amateur player draft. Journal of Productivity Analysis, 35(1), 25-35.

Berri, D. J., \& Simmons, R. (2011). Catching a draft: On the process of selecting quarterbacks in the National Football League amateur draft. Journal of Productivity Analysis, 35(1), 37-49.

Burgess, D., Naughton, G., \& Hopkins, W. (2012). Draft-camp predictors of subsequent career success in the Australian Football League. Journal of Science and Medicine in Sport, 15(6), 561-567.

Cnaan, A., Laird, N., \& Slasor, P. (1997). Tutorial in biostatistics: Using the general linear mixed model to analyse unbalanced repeated measures and longitudinal data. Statistics in Medicine, 16, 2349-2380.

Cobley, S., Baker, J., Wattie, N., \& McKenna, J. (2009). Annual age-grouping and athlete development. Sports Medicine, 39(3), 235-256.

Coutts, A. J., Kempton, T., Sullivan, C., Bilsborough, J. C., Cordy, J., \& Rampinini, E. (2014). Metabolic power and energetic costs of professional Australian Football match-play. Journal of Science and Medicine in Sport, 18(2), 219-224. 
Coutts, A. J., Kempton, T., \& Vaeyens, R. (2014). Relative age effects in Australian Football League national draftees. Journal of Sports Sciences, 32(7), 623-628.

Gray, A. J., \& Jenkins, D. G. (2010). Match analysis and the physiological demands of Australian Football. Sports Medicine, 40(4), 347-360.

Güllich, A., Hardy, L., Kuncheva, L., Laing, S., Barlow, M., Evans, L., ... Warr, C. (2019). Developmental biographies of Olympic super-elite and elite athletes-a multidisciplinary pattern recognition analysis. Journal of Expertise, 2(1), 23-46.

Hiscock, D., Dawson, B., Heasman, J., \& Peeling, P. (2012). Game movements and player performance in the Australian Football League. International Journal of Performance Analysis in Sport, 12, 531-545.

Kuzmits, F. E., \& Adams, A. J. (2008). The NFL combine: Does it predict performance in the National Football League? The Journal of Strength and Conditioning Research, 22(6), 1721-1727.

McIntosh, S., Kovalchik, S., \& Robertson, S. (2018a). Examination of player role in the Australian Football League using match performance data. International Journal of Performance Analysis in Sport, 18(3), 451-462.

Mclntosh, S., Kovalchik, S., \& Robertson, S. (2018b). Validation of the Australian Football League player ratings. International Journal of Sports Science and Coaching, 13(6), 1064-1071. 1747954118758000.

Mitchell, H., Stavros, C., \& Stewart, M. F. (2011). Does the Australian Football League draft undervalue indigenous Australian footballers? Journal of Sports Economics, 12(1), 36-54.

Mooney, M., O'Brien, B., Cormack, S., Coutts, A. J., Berry, J., \& Young, W. (2011). The relationship between physical capacity and match performance in elite Australian football: A mediation approach. Journal of Science and Medicine in Sport, 14(5), 447-452.

Mulholland, J., \& Jensen, S. T. (2014). Predicting the draft and career success of tight ends in the National Football League. Journal of Quantitative Analysis in Sports, 10(4), 381-396.

Pyne, D., Gardner, A., Sheehan, K., \& Hopkins, W. (2005). Fitness testing and career progression in AFL football. Journal of Science and Medicine in Sport, 8(3), 321-332.

Robertson, S., Woods, C., \& Gastin, P. (2014). Predicting higher selection in elite junior Australian rules football: The influence of physical performance and anthropometric attributes. Journal of Science and Medicine in Sport, 18(5), 601-606.

Stewart, M., Mitchell, H., \& Stavros, C. (2007). Moneyball applied: Econometrics and the identification and recruitment of elite Australian footballers. International Journal of Sport Finance, 2, 231-248.
Stewart, M. F., Stavros, C., Phillips, P., Mitchell, H., \& Barake, J. P. (2016). Like father, like son: Analysing Australian football's unique recruitment process. Journal of Sport Management, 30, 672-688.

Sullivan, C., Bilsborough, J. C., Cianciosi, M., Hocking, J., Cordy, J., \& Coutts, A. J. (2013a). Factors affecting match performance in professional Australian football. International Journal of Sports Physiology and Performance, 9(3), 561-566.

Sullivan, C., Bilsborough, J. C., Cianciosi, M., Hocking, J., Cordy, J., \& Coutts, A. J. (2013b). Match score affects activity profile and skill performance in professional Australian football players. Journal of Science and Medicine in Sport, 17(3), 326-331.

Teramoto, M., Cross, C. L., Rieger, R. H., Maak, T. G., \& Willick, S. E. (2017). Predictive validity of National basketball association draft combine on future performance. The Journal of Strength and Conditioning Research, 32(2), 396-408.

Teramoto, M., Cross, C. L., \& Willick, S. E. (2016). Predictive value of National Football League scouting combine on future performance of running backs and wide receivers. The Journal of Strength and Conditioning Research, 30(5), 1379-1390.

Tribolet, R., Watsford, M. L., Coutts, A. J., Smith, C., \& Fransen, J. (2019). From entry to elite: The relative age effect in the Australian football talent pathway. Journal of Science and Medicine in Sport, 22(6), 741-745.

Vaeyens, R., Lenoir, M., Williams, A. M., \& Philippaerts, R. M. (2008). Talent identification and development programmes in sport: Current models and future directions. Sports Medicine, 38(9), 703-714.

West, B. T., Welch, K. B., \& Galecki, A. T. (2014). Linear mixed models: A practical guide using statistical software (2nd ed.). Broken Sound Parkway, NW: CRC Press.

Whittingham, M. J., Stephans, P. A., Bradbury, R. B., \& Freckleton, R. P. (2006). Why do we still use stepwise modelling in ecology and behaviour? Journal of Animal Ecology, 75, 1182-1189.

Woods, C., Joyce, C., \& Robertson, S. (2015). What are talent scouts actually identifying? Investigating the physical and technical skill match activity profiles of drafted and non-drafted U18 Australian footballers. Journal of Science and Medicine in Sport, 19(5), 419-423.

Woods, C., Raynor, A. J., Bruce, L., \& McDonald, Z. (2016). Discriminating talent-identified junior Australian football players using a video decision-making task. Journal of Sports Sciences, 34(4), 342-347.

Woods, C., Veale, J., Collier, N., \& Robertson, S. (2016). The use of player physical and technical skill match activity profiles to predict position in the Australian Football League draft. Journal of Sports Sciences, 35(4), 325-330. 